Tür Turizm Araştırmaları Dergisi
2021,5(1): $737-753$.
ISSN: $2587-0890$ Dergi web sayfasi: $\underline{\text { https://www.tutad.org }}$

\title{
İngilizce ve Türkçe Kelimelerin Fonolojik ve Semantik Benzerliklerinin Kelime Öğretimine Katkısı: S.Ü. Silifke-Taşucu MYO, Turizm ve Otel İşletmeciliği Programı Örneği*
}

\author{
Öğr. Gör. Dr. Mürsel KAYA, Selçuk Üniversitesi, Silifke-Taşucu Meslek Yüksekokulu, Konya, e- \\ posta: murselkaya@selcuk.edu.tr \\ ORCID: https://orcid.org/0000-0003-3420-0222
}

Dr. Öğr. Üyesi Nazli GÜNDÜZ, Ankara Hacı Bayram Veli Üniversitesi, Edebiyat Fakültesi, Ankara, e-posta: nazli.gunduz@hbv.edu.tr ORCID: https://orcid.org/0000-0001-8728-0372

Öz

Turizm özellikle gelişmekte olan ülkelerin ekonomileri için hayati önem taşıyan bir sektördür. Dolayısıyla turizm gelirleri GSMH içinde önemli bir yer tutar. Emek-yoğun bir sektör olan turizmde dil yetkinliklerine sahip insan kaynakları önemli bir konudur. Birçok turizm çalışanı mesleki yeterliliklere sahip olmasına rağmen özellikle yabancı müşteriler ile iletişim zorlukları yaşamasına neden olacak dil becerileri yetersizliği sahip olabilmektedir. Çoğu turizm ve ağırlama hizmetleri, kişiler arası etkileşim yoluyla sağlanır. Bu, sadece hizmet sağlayıcıların ve yöneticilerin tutum ve davranışlarının değil aynı zamanda onların dil yeteneklerine de bağlı olduğu anlamına da gelir. Sözcük bilgisi yabancı dil öğreniminde, öğretiminde ve kullanımında üstesinden gelinmesi gereken önemli bir sorun olarak karşımıza çıkmaktadır. Sözcükler duygu ve düşüncelerimizi, isteklerimizi içeren mesajları karşımızdakine ulaştırmanın yegâne araçlarıdır. Bu araştırma hem ana dil hem de öğrenilen yabancı dilin fonolojik ve semantik benzerliklerini kullanarak sözcük öğretiminin yeni bir metodunu araştırmayı hedeflemektedir. Bu araştırma, yabancı dili yoğun bir biçimde kullanmak durumunda olan Turizm ve Otel İşletmeciliği öğrencilerinin katılımı ile yapılmıştır ve sadece semantik ve fonolojik benzerlikleri olan sözcüklerin öğrenim kolaylığı sağlayıp sağlamadığını ayrıca bu tür sözcüklerin ihtiyaç duyulduğunda ne ölçüde hatırlanabildiğini ölçme amacı taşımaktadır. Bu amaçla Silifke-Taşucu MYO, Turizm ve Otel İşletmeciliği programına kayıtlı 45 örgün eğitim öğrencisine araştırma kapsamında belirlenen 30 tanesi araştırmaya özüne uygun semantik ve fonolojik benzerliğe sahip olmak üzere toplam 40 kelime ile uygulanmıştır. Araştırma sonucunda katılımcıların deneysel sözcüklerini farklı zaman dilimlerinde yapılan ölçümlemelerde kontrol sözcüklere göre çok daha belirgin bir düzeyde başarılı bir şekilde anlamlarını bilebildikleri tespit edilmiştir.

* Bu çalışma, birinci yazarın ikinci yazar danışmanlığında hazırladığı Yüksek Lisans tezinden üretilmiştir.

Anahtar Kelimeler: Turizm, Emek-Yoğun, Hizmet Sektörü, Sözcük Bilgisi, Semantik ve Fonolojik Benzerlik.

Makale Gönderme Tarihi: 01.12.2020

Makale Kabul Tarihi: 08.03.2021

\footnotetext{
Önerilen Atıf:

Kaya, M. ve Gündüz, N. (2021). İngilizce ve Türkçe Kelimelerin Fonolojik ve Semantik Benzerliklerinin Kelime Öğretimine Katkısı: S.Ü. Silifke-Taşucu MYO, Turizm ve Otel İşletmeciliği Programı Örneği, Türk Turizm Araşttrmaları Dergisi, 5(1): 737-753.

(C) 2021 Türk Turizm Araştırmaları Dergisi.
} 


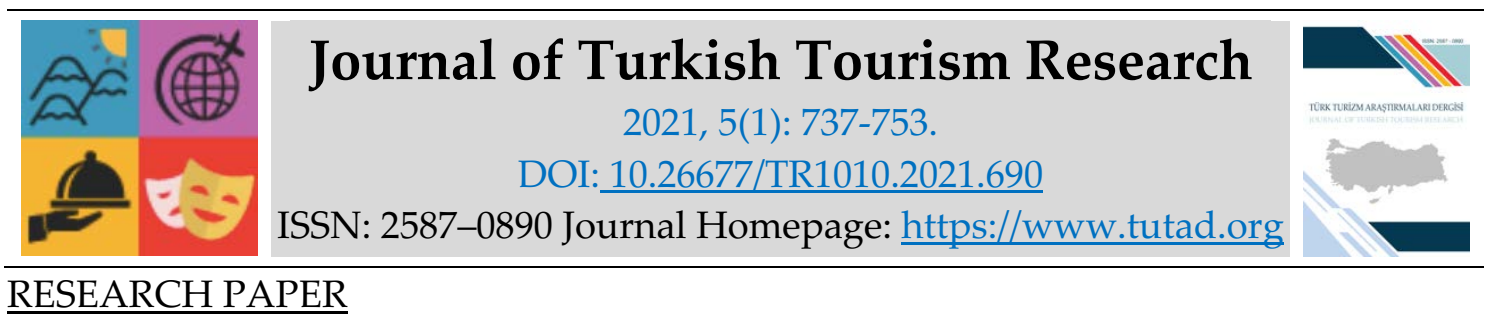

\title{
The Contribution of the Phonological and Semantical Similarities of English and Turkish Words to Vocabulary: Sample of S.Ü. Silifke-Taşucu VSHE, Tourism and Hotel Management Program
}

\author{
Dr. Mürsel KAYA Selçuk University, Silifke-Taşucu Vocational School, Konya, e-mail: \\ murselkaya@selcuk.edu.tr \\ ORCID: https://orcid.org/0000-0003-3420-0222
}

Assistant Prof. Dr. Nazli GÜNDÜZ, Ankara Hacı Bayram Veli University, Faculty of Literature, Ankara, e-mail: nazli.gunduz@hbv.edu.tr ORCID: https://orcid.org/0000-0001-8728-0372

\begin{abstract}
Tourism is a sector which is of vital importance especially for the economies of developing countries. Therefore, the tourism income has a notable portion in GDP. For a labor-intensive sector like tourism, linguistically capable human resources are an important asset. Tourism personnel who have the professional competence, yet not the linguistic competence, have complications in communication with foreign visitors. Many tourism and accommodation services are carried out via social interaction. This means not only the attitude and behaviour but also the linguistic competence of the service providers and executives carry importance as well. Vocabulary is a noteworthy challenge that is needed to be overcome in foreign language teaching, learning, and usage. Words are the sole instrument via which people convey their emotions, thoughts, and requests. This study aims to analyse a new method of teaching vocabulary, which uses the phonological and semantical similarities of both the native language and the target foreign language. This study, of which the participants consist of students of the Tourism and Hotel Management department, who often find themselves in the intense use of foreign language; solely aims to find whether phonological and semantical similarities in vocabulary facilitate easier learning, and to what extent this vocabulary can be remembered when needed. The study was carried out with 40 words which were specified for the study, 30 of which have the phonological and semantical similarities which suit the objective of the study; by Silifke-Taşucu VSHE, with the target participants being 45 students who are in the Tourism and Hotel Management department. As a result of the study, it was determined that the participants were able to successfully understand the meanings of the experimental words in a much more distinctive level than the nonexperimental words in the measurements made in different time periods.
\end{abstract}

Keywords: Tourism, Labour-Intensive, Service Sector, Vocabulary, Semantical and Phonological Similarity.

Received: 01.12.2020

Accepted: 08.03.2021

Suggested Citation:

Kaya, M. and Gündüz, N. (2021). The Contribution of the Phonological and Semantical Similarities of English and Turkish Words to Vocabulary: Sample of S.Ü. Silifke-Taşucu VSHE, Tourism and Hotel Management Program, Journal of Turkish Tourism Research, 5(1): 737-753.

(C) 2021 Türk Turizm Araştırmaları Dergisi. 


\section{Gíriş}

Turizm endüstrisi işsizlik ve dış ödemeler dengesi gibi katkılarından dolayı, turizm gelişmekte olan ülkeler için hayati bir sektör haline gelmiştir. Sadece gelişmekte olan ülkeler değil gelişmiş ekonomilere sahip ülkeler de uluslararası turizm gelirlerine oldukça çok önem vermektedirler (Dieke, 1988; Tosun, 1999; Moisa, 2015). Turizm ve yabancı dil arasında önemli bir bağlantı vardır; böylesine önemli bir sektör olan turizm, emek-yoğun bir sektör olmasından dolayl, sektör çalışanlarının kabul edilebilir seviyede yabancı dil yeteneklerine sahip olmasının beklenmesi doğaldır çünkü çoğu turizm ve ağırlama hizmetleri bireyler arası etkileşim yoluyla sağlanmaktadır. $\mathrm{Bu}$ ise misafirlerin verilen hizmetlerden memnun olması için servis sağlayıcılarının ve onların yöneticilerinin sadece sergiledikleri tavır ve davranışları değil aynı zamanda dil becerilerini doğru kullanmalarını ön plana çıkarmaktadır (Amoah ve Baum, 1997; Christou, 1999; Little ve Dean, 2006; Rhodes, 2006; Zagonari, 2009; Rao, 2019). Turizm ve yabanc1 dil arasındaki çok yakın bir ilişki olduğu bilinen bir olgudur. Emek-yoğun turizm sektöründe yabancı dil bilmek adeta bir zorunluluktur. Fakat sektörde istihdam edilen insan gücünde bir yabancı dili (özellikle İngilizceyi) kabul edilebilir seviyede konuşabilmek bir problem haline gelmiştir. Sorunun kaynağı ise sadece dilbilgisi eksikliğinden değil sözcük bilgisi eksikliğinden de kaynaklandığı düşünülmektedir.

Yabancı dil bilmenin, yabancı dili yeteneklerini kullanarak iletişim kurabilmeleri turizm işgücü için çok önemli olduğu bilinen bir gerçektir; ayrıca turizmde istihdam edilecek olan bu bireylerin kabul edilebilir seviyede yabancı dil bilmesi kabul edilebilir seviyede sözcük bilgisine sahip olmasından geçtiği söylenebilir. Hal böyle iken, sözcük bilgisi öğrenme ve öğretme yabancı dil eğitiminde önemli bir yer tutmasına rağmen halen sorun olmaya devam etmektedir. Maalesef sözcükler zor öğrenilmekte ama çok kolay unutulmaktadır. Üniversitelerin ön lisans seviyesindeki turizm programlarında İngilizce sözcük bilgisine yönelik çok az çalışmanın yapılması da bu çalışmayı önemini artırmaktadır. Bu çalışma sonuçları itibariyle yabancı dil eğitiminde, öğrencilerin sözcük bilgisini artırmaya yönelik önemli sonuçlar ortaya koyacağına inanilmaktadır.

İngilizce bugün dünyada anadili farklı birçok milletin "Lingua Franca" dediğimiz ölçüde yaygın konuşabildiği bir yabancı dil olarak kabul edilmektedir (Cloudia Ho, 2020). İngilizce akademik hayatta, iş hayatında, turizm, ticaret ve uluslararası politik arenada ve birçok alanda yaygın olarak kullanılmaktadır (Liao, Hsu, Lee ve Yang, 2017; Salameh Alomoush, 2018). İngilizce, bu alanlar için önemlidir ama turizm sektörü için adeta vazgeçilmez bir dil halini almıştır (Cloudia Ho, 2020). Turizm çalışanlarının dünya çapında bir yaygınlığa sahip bu dili alanlarına ait doğru sözcüklerle öğrenmesi adeta bir zorunluluk haline gelmiştir (Fujita, Terui, Araki ve Naito, 2017).

\section{LITERATÜR}

"Sözcükler" düşünmenin, fikir ve duyguları ifade etmenin ve dünya hakkında yeni bilgiler edinmenin araçlarıdır. Sözcükler, öğrenmenin ve sözcük bilgisini geliştirmenin yegâne kaynağ 1 ve dil öğrenmenin en önemli parçası olduğundan yabancı dil öğretiminde öncelikli konular arasında yer almaktadır (Alipoor ve Jadidi, 2016). Kelime öğrenimi dil öğrenim süreci devam ettiği müddetçe devam eden bir süreçtir çünkü daha fazla kelime öğrenildikçe okuduğunu ve dinlediğini anlayan birey üretken beceriler dediğimiz yazma ve konuşma yetenekleri de daha fazla gelişecektir. Kelime haznesi gelişmesi bireyin kendini ne kadar iyi ifade gücüyle doğru orantılıdır, bir başka ifadeyle kelime haznesinde kelime sayısı fazla olan bireyler kendilerini en doğru ve iyi ifade edebilirler (Heng, 2011). Sözcük bilgisi hem ana dil hem de yabancı dil araştırmacılarının üzerinde çokça araştırma yaptığı bir alandır (Frederiksen, 1982; Grabe, 1991, 
Tovar Viera, 2016). Sözcük bilgisi içeren testler, belirli madde türlerinin etkinliğinin incelenmesi (Chapelle, 1994; Perkins ve Linville, 1987, Alqahtani, 2015; Tovar Viera, 2016) ve hazırlık aşamasında sözcük testi alanının kapsamlı incelenmesi gibi bazı sözcük testlerinin yapı geçerliliği çalışmaları ile artık hak ettiği ilgiyi görmektedirler (Nation, 1990; Henning, 1991; Laufer, 1997; Alqahtani, 2015; Tovar Viera, 2016).

Okuduğunu anlayabilmek için sözcük bilgisinin elzem olmasından dolayı öğrencinin sözcük bilgisi akademik bir başarı arasında çok güçlü bir bağ bulunmaktadır. Dahası, öğrenci performansını ölçmek için kullanılan yüksek riskli standartlaştırılmış testlerin sözlü bölümleri temelde sözcük bilgisi ve okuduğunu anlama testlerinden oluşmaktadır. Stahl (1999) okuduğunu anlama ve sözcük bilgisinin güçlü bir şekilde ilişkili olduğunu öne sürmektedir. Biemiller (2001) ise ilkokulda edindikleri sözcük bilgisi ile öğrencilerin lisede okudukları metinleri ne kadar iyi anlayabileceklerini tahmin edebileceğini vurgulayarak yabancı dil öğreniminde sözcük bilgisinin ve öğretiminin önemli bir konu olduğunu savunmuştur.

Öğrencilerinin sözcükleri çalıştıkları halde çok zor öğrendikleri ama kolayca unuttuklarından yakınmaları yabancı dil öğretmenlerinin sıkça karşılaştıkları bir durumdur. Sözcük öğrenimine özel bazı stratejiler vardır. Bu stratejileri ortaya çıkarmak için birçok araştırma yapıl olup, bunlar genellikle 3 alan üzerine yoğunlaşmışlardır (Heng, 2011):

- Genel kelime öğrenimi stratejileri,

- Kelimenin türüne göre sinıflandırarak(taksonomi) kelime öğrenimi stratejileri,

- En sık kullanılan kelimeleri tespit ederek kelime öğrenimi bu kelimler üzerinde yürütme stratejileri.

Genel kelime öğrenimi stratejileri, genellikle bilişsel, biliş-ötesi ve sosyal stratejileri içerir. Hedge (2000) öğrencilerin genellikle anahtar kelimeler, ilişik kurma ve kelimeleri gruplandırarak öğrenme gibi bir dizi bilişsel stratejileri kullandıklarını ifade eder ve "Bilişsel" stratejiyi yeni kelimeleri öğrenme, anlama, sınıflandırma ve depolama ilgili beynin bir operasyonu olarak tanımlar. Schmitt (1997) de benzer bir şekilde "Bilişsel" stratejiyi yazılı ve konuşma tekrarlarını da kapsayacak şekilde kelime listeleri ve flaş kartların yaygın kullanıldığı bir strateji olarak ifade eder. Sınıf içinde not almak ve sadece kelime öğrenimine yönelik defter tutmak da birçok öğretmen ve yazar tarafından faydalı görülmekte ve tavsiye edilmektedir (Henge, 2011). Schmitt (1997)'e göre biliş-ötesi stratejiler, öğrenciler tarafından tüm öğrenme süreçleri dikkate alınarak ve kendi kendilerine kontrol ve değerlendirme sonucunda kendi öğrenme süreçlerini oluşturarak kullanılan stratejilerdir. Sosyal stratejiler ise öğretmenin veya öğretmenin oluşturduğu gruplardaki üyelerin birbirine kelime anlamlarını, eş anlamlı veya zıt kelimelerin anlamlarını veya diğer tanımları bir birine sormasını içeren stratejilerdir.

Ghanal (2007) tüm bu stratejilerin yanında kelime öğrenimi ile ilgili süreçlerde yabancı dil öğrencilerinin bağımsız hareket edebilmesi veya davranabilmesinin hayati önem taşıdığına işaret eder. Eğer yabancı dil öğrencisi bağımsız davranabilirse, kendi öğrenme stratejisini oluşturma konusunda kendi kendini yönlendirme yeteneğine sahip olabileceğini ve bu konuda kendine güven duygusu kazanabileceğini iddia eder. Öğretmenler kelime örenimin önemi konusunda öğrencilerin dikkatini çekmeli, kelime öğrenme stratejileri ile alakalı öğrencilerin farkındalığını artırılmalıdır; çünkü bu stratejiler öğrencilerin öğrenilen yabancı dilin etkili ve verimli öğrenilmesinde çok etkili olduğu bilinen bir gerçektir (Hismanoğlu, 2000).

Hunt ve Beglar (2004) diğer stratejilerden bağımsız olarak öğrencilerin konuşma veya metin içeriğinden kelimenin anlamını tahmin etmeleri için çaba sarf etmesi gerektiğini ifade ederler ve bu konuda öğretmenlerin öğrencileri teşvik etmelerini de önerirler. Okurken veya dinlerken kelimler hakkındaki eşdizimlilik, dilbilgisi ve edimsel bilgilerin kelimenin anlamını tahmin için çok değerli bilgiler içerdikleri öğrencilere öğretilmelidir. 
Taksonomik kelime öğrenimi stratejileri birçok araştırmacının dikkatini çekmektedir. Taksonomik kelime öğrenme stratejileri iki temel stratejiyi içinde barındırır: Keşfetme stratejileri ve pekiştirme stratejileri. Keşfetme stratejileri saptama ve sosyal stratejileri içerirken pekiştirme stratejileri sosyal stratejilerin yanı sıra bilişsel, biliş-ötesi ve hafıza stratejilerini kapsamaktadır (Schmitt,1997). Akbari ve Tahririan (2009) taksonomi stratejisini kelime öğreniminde en teferruatlı ve kelime öğrenimi stratejilerinin en oturmuş şekli olduğunu ifade etmişlerdir.

En yaygın kullanılan kelimeleri öğrenme stratejisi hakkında özellikle Hong Kong'da Çinli lise seviyesinde öğrencilerin katıldığ 1 araştırmalar yapılmıştır. Bu araştırmaların sonucunda en yaygın kelimeler stratejisinin barındırdığı 4 alt strateji tespit edilmiştir (Lip, 2009):

- Kelimeyi zihinde heceleyerek tekrar etmek,

- Kelimeyi ses segmentlerine ayırarak analiz etmek,

- Bu kelimeleri hatırlatacak bir proje yapmak,

- Sınıf arkadaşlarına bu kelimenin anlamını sormak.

Yabancı dil öğrencileri hangi stratejiyi kullanırsa kullansın bağımsızlığı, sorumluk alması ve sözlük kullanım alışkanlığı edinmesi önemlidir. Özellikle artık elektronik sözlükler bu konuda çok kullanım kolaylığı sağladığı günümüzde öğrencilerin dikkati, hazırlık olması, kendi kendini kontrol etmesi ve yönetmesi, tekrar etmesi, not alması, zihinde resimleme ve kendi dilinde anlamlandırması sosyal ve duygusal stratejilere göre yaygın stratejiler olarak görünmektedir.

Tüm bu stratejilerin dışında yabancı dili öğrenen bireylerin anadilinin özelliklerini kullanarak yeni ve olağan dışı stratejiler de kullanılmaktadır. Hafıza, öğrenilmiş bilgilerin beyinde depolandığ1 ve gerektiğinde buradan çağrıldığ kabul edilen yere denmektedir. Bilgilerin işleniş biçimi, geri çağırma ve unutma doğrudan hafızayla ilgilidir. Bu noktadan hareketle hafızanın bireyin yaşantılarına dair dosyalar olduğunu söylemek yerinde olacaktır (Batur, 2008). Bireylerin hızlı ögrenmelerine ve daha iyi hatırlamalarına yardımcı olan "Nimonik" (belleksel, hatırlatıcı, anımsatıcı) kelime öğrenimi stratejileri bunlardan biridir. Bu teknikler hafızadaki bilgiyi geri çağırmak için bazı işitsel ve anlamsal ipuçlarını bünyelerinde barındırırlar. Thompson (1987) nimoniklerin zorlanmadan benimsenebileceğini ve uzun vadeli hafızada tutma sağlayabileceğini ifade etmiştir.

Ortografik sözcük öğrenimi, bireyin yazım dilinde sözcügün ortografik yapısına olan aşinalığına dayalı bir sözcük öğrenme şeklidir (Georgiou, Parrila ve Papadopoulos, 2008). Başka bir deyişle, ortografik sözcük öğrenimi; "ortografik simgeleri oluşturma, saklama ve erişme becerisi" olarak tanımlanmıştır (Stanovich ve West, 1989). Bu sözcük öğrenme şeklinde, bireyin yazım ve konuşma dilinde bulunan harf kalıplarına ilişkin bilgisini kapsar ve sözcük okuma ve konuşma akıcılı̆̆ına katkıda bulunur (Özata ve Haznedar, 2015). Tabi ki ortografik sözcük öğreniminde de diğer tekniklerde olduğu gibi başarı bireysel yetenek ve becerilere göre farklılık gösterebilir (Asadi vd., 2017; Deacon vd., 2014). Özellikle birey, zaman kısıtlamasının olduğu veya hızlı cevap vermesi gerektiği durumlarda, sesbirim yerine, harf dizileri gibi daha büyük parçalardan yararlanarak okuma işini gerçekleştirir (Georgiou vd., 2008). Bu nedenle, ortografik sözcük öğrenme, bireyin sözcük okuma ve konuşma akıcılığını arttıran bir faktör olarak ortaya çıkar (Papadopoulos vd., 2016).

Bu çalışmada kullanılan teknik veya yöntemin öğrenilen yabancı dil ile akustik ve 'ortografik' (yazım, imla) benzerliği olan anahtar sözcük yönteminden veya nimonik sözcük öğrenimi tekniğinden farklı daha önce kullanılmayan bir teknik olduğu bilinmelidir. Bahse konu olan teknikler ana dilde sözcük öğrenimde ve yabancı dilde sözcük öğreniminde kullanıldığı bir gerçektir fakat bu çalışmada kullanılan teknik adı geçen tekniklerden farklı olarak; ana dil ile yabancı dildeki sözcükler arasında sadece akustik ve ortografik benzerlik değil ayn zamanda işlevsel ve anlamsal benzerlikleri de kullanmaktadır. Örneğin İngilizcedeki "Save" sözcüğü hem 
"Sav-mak" sözcüğünün kökü olan "Sav" ile ses bakımından hem de "Savuşturmak, korumak" anlamında işlevsel olarak da benzerlik göstermektedir. Bazen hem ses benzerliği ve işlevsel benzerlik bir arada olamayabilir, bu durumda hangi benzerlik mevcut ise sözcük öğrenimi o benzerlik üzerinden yürütülmesi gerekmektedir. Örneğin, İngilizcedeki "Eğitmen" veya "Terbiyeci" anlamındaki "Tamer" sözcügü Türkçedeki "Eğiterek adam eden, tam er gibi yapan" anlamıla işlevsel benzerlik göstermektedir.

\section{YÖNTEM ve TASARIM}

Yabancı dil bilmek turizm çalışanları için çok önemlidir; ayrıca turizmde istihdam edilecek olan bu bireylerin kabul edilebilir seviyede yabancı dil bilmesi kabul edilebilir seviyede kelime bilgisine sahip olması çalışmayı önemli kılmaktadır. Hal böyle iken, kelime bilgisi öğrenme ve öğretme yabancı dil eğitiminde önemli bir yer tutmasına rağmen halen sorun olmaya devam etmektedir. Maalesef kelimeler zor öğrenilmekte ama çok kolay unutulmaktadır. Üniversitelerin ön lisans seviyesindeki turizm programlarında İngilizce kelime bilgisine yönelik çok az çalışmanın yapılması da bu çalışmayı önemini artırmaktadır. Bu çalışma sonuçları itibariyle yabancı dil eğitiminde, öğrencilerin kelime bilgisini artırmaya yönelik önemli sonuçlar ortaya koyacağına inanılmaktadır.

$\mathrm{Bu}$ çalışmanın amacı ana dil ve öğrenilen yabancı dil arasında fonolojik ve semantik anlam benzerlikleri olan kelimeleri öğrencilerin ne kadar kolay öğrenip ne kadar süre sonra hatırlayabildiklerini ölçmektir. Dolayısıyla fonolojik ve semantik benzerliklerin kelime bilgisini öğretimine veya öğrenimine katkısını araştırmayı amaçlamaktadır.

Bu araştırma sadece Selçuk Üniversitesi, Silifke-Taşucu Meslek Yüksekokulu, Turizm ve Otel İşletmeciliği Programında haftada 4 saat İngilizce dersleri olan “Başlangıç Seviyesindeki” öğrenci grubunu kapsamaktadır. Başka ön lisans veya lisans seviyesindeki programlarda ve başka dil seviyelerine sahip öğrenciler için aynı sonuçlara ulaşılamayabilir. Bu tekniğin bütün kelimelere uygulanamayışı; sadece fonolojik, semantik özellikleri ve kullanım fonksiyonu bakımından benzerlikleri olan kelimeler için kullanılması da önemli bir sınırlılık olarak karşımıza çıkmaktadır.

Birçok yabancı dil öğrencisi kelime öğrenmede ve öğrendiği sözcüğü içselleştirmede sorun yaşamaktadır. Zor öğrenilen kelimeler genellikle çok kolay unutulmaktadır veya ihtiyaç duyulduğu anda hatırlanamamaktadır. Bu çalışma, yabancı kelimeler "Nasıl kolay öğrenilir?" ve "Hafızada kalma süreleri nasıl uzatılır?" sorularına cevap aramaktadır. Bu sorunsala dayanarak aşağıdaki araştırma sorularına cevap aranmak istenmiştir:

1. Türkçe ve İngilizce kelimelerin fonolojik ve semantik benzerliği, kelime öğretiminde/öğrenilmesinde ne kadar etkilidir?

2. Türkçe ve İngilizce kelimelerin fonolojik ve semantik benzerliği, kelimelerin öğrencilerin hafızasında kalmasında ne kadar etkilidir?

Bu çalışma, Türkçe ve İngilizce kelimeler arasındaki semantik ve fonolojik benzerliklerin, kelime öğrenmedeki erken ve geç etkileri üzerine deneysel bir bakış sunmaktadır. Bu araştırmayla fonolojik ve semantik benzerliğin kelime öğretimi, kelimelerin kolaylıkla hatırlanması ve tanınması arasında bir ilişkinin olduğu kanıtlanmaya çalışılmıştır. Bir tarafta semantik ve fonolojik benzerlikleri olan, diğer tarafta bu benzerliklere sahip olmayan iki farklı kelime türü karşılaştırılarak hangisinin diğerine göre öğrenme ve hatırlanma avantajlarına sahip olduğu tespit edilmeye çalışılmıştır. Bunun için S.Ü. Silifke-Taşucu MYO, Turizm ve Otel İşletmeciliği Programinda ön lisan eğitimini sürdüren ve haftada 4 saat İngilizce dersleri alan 45 gönüllü 
öğrenci araştırmamıza katılmıştır. Katılımcılar, araştırmacının mesleki tecrübe ve ölçümlerine göre Elementary (Başlangıç) seviyesindedirler. Araştırmaya konu olan kelimeleri elde etmek için öncelikle içinde 54 adet kelime bulunan bir liste öğrencilere dağıtılmış ve her bir öğrencinin önceden anlamını bildiği kelimeler tespit edilmiş ve katılımcıların hiç anlamını bilmediği 40 kelime böylece araştırmaya konu edilmiştir. Bu 40 sözcüğün 30 tanesi Türkçe karşılıklarında fonolojik ve semantik benzerlik olan ve 'deneysel' olarak tanımlanan İngilizce kelimelerden oluşmaktadır. Diğer 10 tanesi ise Türkçe karşılıklarında hiçbir fonolojik ve semantik benzerlik taşımayan ve 'kontrol kelimeleri' olarak tanımlan kelimelerdir. Deneysel kelimeler öğrencilere anlatılırken bu benzerliklere vurgu yapılan özel bir teknikle anlatılmıştır. Kontrol kelimeleri ise sadece anlamları verilerek geleneksel yöntemlerle öğretilmiştir. Öğretim oturumlarının hemen ardından katılımcılar "Ön" teste tabi tutularak, kelimelerin hatırlanma oranları ölçülmüştür. Bu ilk testten 2 hafta sonra "Son" teste daha tabi tutularak, kelimelerin hatırlanma oranları ölçülmüştür. Son olarak yine 2 hafta sonra çoktan seçmeli bir tanıma testine tabi tutulmuşlardır. Dolayısıyla "ilk test" ile "son test" arasında 2 hafta, son aşamada yapılan çoktan seçmeli "tanıma testi" ile birlikte toplam 4 haftalık bir süre geçmiştir. Elde edilen veriler SPSS (Statistical Package for the Social Sciences) programına yüklenmiş ve analiz edilmiştir.

$\mathrm{Bu}$ çalışma hem Türkçe hem de İngilizce kelimelerin arasındaki fonolojik ve semantik benzerlikleri avantaja dönüştürerek kelime bilgisi öğretimine nasıl bir katkı sağlanabileceğini ölçmeyi amaçlamaktadır. Bu nedenle bu araştırma hem Türkçesi hem de İngilizcesi fonolojik ve semantik benzerliklere sahip olan kelimeler üzerinden yürütülmüştür. Bu çalışmayı yürütmek için İngilizce-Türkçe Redhouse (Avery ve Bezmez, 1996) sözlüğünde deyim ve teknik terimlerden oluşan 70.000 kelime taranmış ve 527 tane İngilizce kelimelerin Türkçe karşılığında fonolojik ve semantik benzerlik tespit edilmiştir.

Katılımcılar Selçuk Üniversitesi, Silifke-Taşucu Meslek Yüksekokulu, Turizm ve Otel İşletmeciliği Programı öğrenim gören 21 erkek ve 24 kadın toplam 45 öğrenciden oluşmaktadır. Yaş aralıkları 18- 40 yaş arasında değişmektedir. Hepsinin anadili Türkçedir. Katılımcılar 20072008 eğitim öğretim yılı, Bahar yarıyılında haftada 4 saat zorunlu İngilizce dersi almaktadırlar. Öğrencilerin İngilizce ile ilgili farklı geçmişleri olmasına rağmen genellikle başlangıç seviyesindedirler. Katılımcılar bu programa kabul edilmek için üniversiteye giriş sınavında herhangi bir İngilizce sınavına tabi tutulmamışlardır. Katılımcı 45 öğrenciye, içinde 30 Türkçe karşılıkları ile fonolojik ve semantik benzerliği olan, 10 tanesi bu türden bir benzerliği olmayan toplam 40 İngilizce kelime liste verilmiştir. Bknz Tablo 1.

Tablo 1'de Türkçe karşılıklarında fonolojik ve semantik benzerlikleri olan kelimeler öğrencilere anlatıldığı şekliyle, benzerliklerinin vurgulandığı haliyle verilmiştir. Benzerlikler taşımayan 10 kontrol sözcügü 30 fonetik ve semantik benzerliği olan deney kelimeleri arasına rastgele serpiştirilmiştir. Kelimelerin seçiminde aşağıdaki kriterlere uyulmuştur:

- Kelimeler isimler, sıfatlar ve fiillerden oluşmaktadır;

- Kelimelerin hece sayısı dikkate alınmamıştır;

- Deneysel kelimelerin Türkçe karşılıklarında fonolojik, semantik ve işlevsel benzerlikler bulunmaktadır;

- Kontrol kelimelerinin Türkçe karşıllıklarında fonolojik, semantik ve işlevsel benzerlikler olmamasına dikkat edilmiştir. 
Tablo 1. Testlerde Kullanılan İngilizce kelimeler ve Türkçe açıklamaları

\begin{tabular}{|c|c|c|c|c|c|}
\hline $\begin{array}{l}\text { Öğretilmek } \\
\text { istenen } \\
\text { İngilizce } \\
\text { Kelime }\end{array}$ & $\begin{array}{c}\text { Okun } \\
\text { uşu }\end{array}$ & Öğrenciye Anlatma Şekli & $\begin{array}{c}\text { Öğretilmek } \\
\text { istenen } \\
\text { İngilizce } \\
\text { Kelime }\end{array}$ & Okunuşu & $\begin{array}{l}\text { Öğrenciye } \\
\text { Anlatma } \\
\text { Şekli }\end{array}$ \\
\hline Bosh & /boş/ & Boş laf, saçma sapan & Toupee & /tup/ & $\begin{array}{l}\text { Peruk. Adam } \\
\text { TePesindeki } \\
\text { keli peruk ile } \\
\text { örttü. }\end{array}$ \\
\hline Cerise & /seriz/ & KiRaZ kırmızısı & Saliva & /selayva/ & SaLYa \\
\hline Atavism & $\begin{array}{l}\text { /atavi } \\
\mathrm{zm} /\end{array}$ & ATacilık, soya çekim & Janissary & /caniseri/ & yeniçeri \\
\hline Delirium & $\begin{array}{c}\text { /diliry } \\
\text { 1m/ }\end{array}$ & DeLiRMe hali, çılgınlık & Caique & /kayik/ & $\begin{array}{l}\text { Sandal, } \\
\text { KaYiK }_{1}\end{array}$ \\
\hline Insular & $\begin{array}{c}\text { /insulı } \\
\mathrm{r} /\end{array}$ & $\begin{array}{c}\text { SuLaR içindeki kara parçası, } \\
\text { ada, adalı }\end{array}$ & Splatter & /sıplatır/ & $\begin{array}{c}\text { SiçRatmak, } \\
\text { SeRPmek }\end{array}$ \\
\hline Crimson & $\begin{array}{c}\text { /kirim } \\
\text { Zin/ }\end{array}$ & K1RM1Z1, kıp kırmız1 & Fleck & /filek/ & Benek, LeKe \\
\hline Gaffe & /gaf/ & GaF yapma, pot kırma & Ablution & /obluşıı/n/ & ABdest \\
\hline Horde & /hord/ & Sürü, oRDu gibi kalabalık & Urchin & /örchin/ & $\begin{array}{l}\text { Afacan, } \\
\text { haşarı } \\
\text { HıRÇıN } \\
\text { çocuk }\end{array}$ \\
\hline Palaver & $\begin{array}{c}\text { /palav } \\
\text { ir/ }\end{array}$ & PaLaVRa, & Luscious & /luşız/ & Çok LeZiZ \\
\hline Jade & /ceyd/ & $\begin{array}{l}\text { Yosma, kötü kadın, CaDı gibi } \\
\text { kadın }\end{array}$ & typhon & /tayfun/ & TaYFuN \\
\hline Tamer & $\begin{array}{l}\text { /teymi } \\
\mathrm{r} /\end{array}$ & $\begin{array}{c}\text { Eğitmek, TaM eR yapmak için } \\
\text { eğitim vermek }\end{array}$ & *Incentive & /insentiv/ & Teşvik edici \\
\hline Graze & /greyz & Otlamak, K1Rda ot yemek & *Stern & /stern/ & Sert, katı \\
\hline Attic & /atik/ & $\begin{array}{c}\text { Tavan arası, çatı odası aTıKların } \\
\text { konulduu oda }\end{array}$ & *Invoice & /invoyis/ & Fatura \\
\hline Candour & $\begin{array}{c}\text { /kend1 } \\
\mathrm{r} /\end{array}$ & CaNDan, içten samimi & *Allege & /aleç/ & $\begin{array}{l}\text { İddia etmek, } \\
\text { ileri sürümek }\end{array}$ \\
\hline Pestle & /pesil/ & $\begin{array}{c}\text { Havanda dövmek, PeSTiLini } \\
\text { çıkarmak }\end{array}$ & ${ }^{*}$ Ointment & /oinment/ & Merhem \\
\hline Elegiac & $\begin{array}{c}\text { /eleca } \\
\text { yık/ }\end{array}$ & $\begin{array}{c}\text { Ağıt, mersiye, CiYaKlarak ağıt } \\
\text { yakmak }\end{array}$ & *Streaker & /strikır/ & $\begin{array}{c}\text { Çıplak halde } \\
\text { koşan }\end{array}$ \\
\hline Incubus & $\begin{array}{c}\text { /ink1b1 } \\
\mathrm{s} /\end{array}$ & Karabasan, KaBuS & *Traitor & /treytır/ & Hain \\
\hline Elope & $\begin{array}{c}\text { /eloup } \\
/\end{array}$ & $\begin{array}{l}\text { Aşı11yla kaçmak, ELinden tutarak } \\
\text { sevidiği ile hOPlayarak kaçmak }\end{array}$ & *Intuition & /intuişın/ & Sezgi, önsezi \\
\hline Crook & /kruk/ & $\begin{array}{l}\text { Hirsiz, düzenbaz, kanun } \\
\text { K1 } \mathbf{R}_{\mathbf{1}} \mathbf{K}\end{array}$ & *Thrifty & /tirifti/ & Tutumlu \\
\hline Saponify & $\begin{array}{l}\text { /Saponi } \\
\text { fay/ }\end{array}$ & SaBuNlaşma & *Strenuous & /streniyıs/ & $\begin{array}{l}\text { Yorucu, } \\
\text { çalışkan }\end{array}$ \\
\hline
\end{tabular}

*Türkçe karşıllılarında fonolojik ve semantik benzerlikler taşımayan kontrol kelimeleri

Katılımcıların bu kelimelerin Türkçesini bilip bilmedikleri önceden test edildi çünkü bu kelimelerin Türkçe karşılıklarının katılımcılar tarafından bilinmemesi araştırmanın sağlıklı yürütülmesi için çok önem arz etmektedir. Araştırmaya konu olacak kelimelerin tespiti 
aşamasında katılımcıların anlamını bildiği tespit edilen kelimeler listeden çıkartılmıştır. Geri kalan İngilizce kelimelerden araştırmaya konu olacak kelimeler seçilmiştir. Bu kelimelerden deneysel kelimeler olarak seçilen kelimelerin Türkçe karşılıklarında şaşırtıcı bir seviyede fonetik ve semantik benzerlikleri olmasına dikkat edilmiştir. Bu kelime listesinde deneysel kelimeler bu benzerliklere vurgu yapılarak katılımcılara anlatılmıştır. Kontrol kelimelerin sadece sözlük anlamı söylenilmekle yetinilmiştir.

Belirlenen kelimelerden Türkçe ve İngilizce fonolojik ve semantik benzerlikleri olan kelimeler öğrencilere bu benzerlikleri vurgulanarak, üzerinde durularak anlatılmıştır. Bu anlatım esnasında öğrencilerin not almasına izin verilmiştir. Anlatım bittikten sonra 10 dakika kelimeler üzerinde çalışmaları için izin verilmiştir. 10 dakikalık süre bitiminde hemen katılımcılara "Ön Test" uygulanmıştır. Bu test ile bu kadar kısa bir süre içinde deneysel ve kontrol kelimelerin ne kadarını ne oranda anlamlarını hatırlayabildikleri veya bilebildikleri ölçülmüştür. Bu ön testten iki hafta sonra aynı ders saatinde öğrencilere aynı kelime listesi yeniden verilmiş ve hatırladıkları kelimelerin anlamlarını yazmaları istenerek "Son Test" uygulanmış ve katılımcıların iki hafta sonra araştırmaya konu olan kelimelerin hatırlanması veya bilinmesiyle ilgili performansları ölçülmüştür. Ön testten 4 hafta sonra katılımcılara yine aynı saatte "Tanıma Testi” uygulanmıştır. Tanıma testi çoktan seçmeli olarak hazırlanmıştır ve öğrencilerin 4 hafta sonunda kontrol kelimelerini mi, yoksa deneysel kelimeleri mi daha çok tanıyabilmede başarılı olduğu ölçülmüştür. Testin soru kısmında kelime verilmiş, kendilerine Türkçe karşıllı̆ı ne olabileceğine dört seçenek verilmiştir. Öğrenciler diğer yanlış seçeneklerin arasından doğru seçeneği bulmaları istenmiştir.

\section{BULGULAR}

Elde edilen verilerin güvenilir olup olmadıklarını ölçmek için bir Güvenilirlik testi yapılmıştır: "Ön", "Son" ve "Tanıma" testlerine Croanbach's Alpha güvenilirlik analizleri uygulanmış ve sonuç olarak "Ön" testin güvenilirlik düzeyi 0.91 olarak gerçekleşmiştir. "Son" testin güvenilirlik düzeyi 0.93 ve "Tanıma" testinin güvenilirlik düzeyi ise 0.92 olarak gerçekleşmiştir. Bknz Tablo 2 .

Tablo 2. Güvenilirlik Analizi

\begin{tabular}{|c|c|c|c|}
\hline & Ön Test & Son Test & Tanıma Testi \\
\hline Cronbach's Alpha & .91 & .93 & .92 \\
\hline $\mathrm{N}$ & 45 & 45 & 45 \\
\hline
\end{tabular}

$\mathrm{p}=0,05, \% 95$ olasilıklı, 9.5 hata pay1

\section{Ön Test Sonuçları}

Ses ve anlam benzerliklerinin kelime öğrenimine ve öğretimine olumlu katkısı olup olmadığ1 ortaya çıkarmak için öğrencilere kelimelerin öğretimi için yapılan oturumdan hemen sonra test uygulanmış ve verilere, SPSS betimleyici analiz uygulanarak sonuçlar ortaya konulmuştur. 
Tablo 3. Betimsel Analizlerin Sonuçları

\begin{tabular}{|c|c|c|c|c|c|c|c|c|c|c|c|}
\hline \multicolumn{4}{|c|}{ Ön Test } & \multicolumn{4}{|c|}{ Son Test } & \multicolumn{4}{|c|}{ Tanıma Testi } \\
\hline Kelime & $\mathrm{N}$ & Ort. & $\begin{array}{l}\text { Std. } \\
\text { Sap. }\end{array}$ & Kelime & $\mathrm{N}$ & Ort. & $\begin{array}{l}\text { Std. } \\
\text { Sap. }\end{array}$ & Kelime & $\mathrm{N}$ & Ort. & Std. Sap. \\
\hline Bosh & 45 & 1.000 & 0.00 & Bosh & 45 & 1.000 & 0.000 & Bosh & 45 & 1.000 & 0.000 \\
\hline Cerise & 45 & 1.000 & 0.000 & Gaffe & 45 & 1.000 & 0.000 & Gaffe & 45 & 1.000 & 0.000 \\
\hline Atavism & 45 & 1.000 & 0.000 & Palaver & 45 & 1.067 & 0.252 & Candour & 45 & 1.067 & 0.252 \\
\hline Delirium & 45 & 1.220 & 0.491 & Candour & 45 & 1.067 & 0.252 & Palaver & 45 & 1.067 & 0.252 \\
\hline Insular & 45 & 1.220 & 0.491 & Delirium & 45 & 1.067 & 0.252 & Delirium & 45 & 1.067 & 0.252 \\
\hline Crimson & 45 & 1.440 & 0.208 & Atavism & 45 & 1.067 & 0.252 & Atavism & 45 & 1.067 & 0.252 \\
\hline Gaffe & 45 & 1.440 & 0.208 & Horde & 45 & 1.090 & 0.288 & Horde & 45 & 1.089 & 0.288 \\
\hline Horde & 45 & 1.440 & 0.208 & Cerise & 45 & 1.089 & 0.288 & Cerise & 45 & 1.089 & 0.288 \\
\hline Palaver & 45 & 1.440 & 0.208 & Jade & 45 & 1.133 & 0.344 & Jade & 45 & 1.133 & 0.344 \\
\hline Jade & 45 & 1.067 & 0.252 & Attic & 45 & 1.133 & 0.344 & Insular & 45 & 1.133 & 0.344 \\
\hline Tamer & 45 & 1.067 & 0.252 & Insular & 45 & 1.133 & 0.344 & Attic & 45 & 1.133 & 0.344 \\
\hline Graze & 45 & 1.067 & 0.252 & Tamer & 45 & 1.156 & 0.367 & Tamer & 45 & 1.156 & 0.367 \\
\hline Attic & 45 & 1.067 & 0.387 & Elegiac & 45 & 1.178 & 0.387 & Elegiac & 45 & 1.178 & 0.387 \\
\hline Candour & 45 & 1.089 & 0.288 & Janissary & 45 & 1.200 & 0.405 & Janissary & 45 & 1.200 & 0.405 \\
\hline Pestle & 45 & 1.089 & 0.288 & Pestle & 45 & 1.200 & 0.405 & Pestle & 45 & 1.200 & 0.405 \\
\hline Elegiac & 45 & 1.156 & 0.367 & Splatter & 45 & 1.200 & 0.405 & Saliva & 45 & 1.200 & 0.405 \\
\hline Incubus & 45 & 1.156 & 0.367 & Saliva & 45 & 1.200 & 0.405 & Incubus & 45 & 1.200 & 0.405 \\
\hline Elope & 45 & 1.156 & 0.367 & Incubus & 45 & 1.200 & 0.405 & Splatter & 45 & 1.200 & 0.405 \\
\hline Crook & 45 & 1.200 & 0.405 & Crook & 45 & 1.222 & 0.420 & Crook & 45 & 1.222 & 0.420 \\
\hline Saponify & 45 & 1.200 & 0.405 & Elope & 45 & 1.244 & 0.435 & Elope & 45 & 1.244 & 0.435 \\
\hline Toupee & 45 & 1.222 & 0.420 & Crimson & 45 & 1.267 & 0.447 & Crimson & 45 & 1.267 & 0.447 \\
\hline Saliva & 45 & 1.222 & 0.420 & Typhoon & 45 & 1.289 & 0.458 & Typhoon & 45 & 1.289 & 0.458 \\
\hline Janissary & 45 & 1.267 & 0.447 & Toupee & 45 & 1.289 & 0.458 & Toupee & 45 & 1.289 & 0.458 \\
\hline
\end{tabular}




\begin{tabular}{|c|c|c|c|c|c|c|c|c|c|c|c|}
\hline Caique & 45 & 1.267 & 0.447 & Fleck & 45 & 1.311 & 0.468 & Fleck & 45 & 1.311 & 0.468 \\
\hline Splatter & 45 & 1.267 & 0.447 & Urchin & 45 & 1.333 & 0.477 & Urchin & 45 & 1.333 & 0.477 \\
\hline Fleck & 45 & 1.289 & 0.458 & *Streaker & 45 & 1.378 & 0.490 & Saponify & 45 & 1.378 & 0.490 \\
\hline *Stern & 45 & 1.289 & 0.458 & ${ }^{*}$ Allege & 45 & 1.400 & 0.495 & Caique & 45 & 1.400 & 0.495 \\
\hline Urchin & 45 & 1.289 & 0.458 & Saponify & 45 & 1.400 & 0.495 & Luscious & 45 & 1.400 & 0.495 \\
\hline Luscious & 45 & 1.356 & 0.484 & Caique & 45 & 1.422 & 0.500 & *Streaker & 45 & 1.422 & 0.500 \\
\hline *Incentive & 45 & 1.356 & 0.484 & Luscious & 45 & 1.444 & 0.503 & Ablution & 45 & 1.444 & 0.503 \\
\hline Typhoon & 45 & 1.356 & 0.484 & *Traitor & 45 & 1.467 & 0.505 & ${ }^{*}$ Allege & 45 & 1.467 & 0.505 \\
\hline Ablution & 45 & 1.444 & 0.503 & Ablution & 45 & 1.467 & 0.505 & Graze & 45 & 1.467 & 0.505 \\
\hline *Invoice & 45 & 1.467 & 0.505 & Graze & 45 & 1.511 & 0.506 & *Traitor & 45 & 1.511 & 0.506 \\
\hline *Allege & 45 & 1.511 & 0.506 & *Ointment & 45 & 1.600 & 0.495 & *Ointment & 45 & 1.600 & 0.495 \\
\hline *Ointment & 45 & 1.556 & 0.503 & *Invoice & 45 & 1.600 & 0.495 & *Invoice & 45 & 1.600 & 0.495 \\
\hline *Streaker & 45 & 1.578 & 0.500 & *Stern & 45 & 1.644 & 0.484 & ${ }^{*}$ Stern & 45 & 1.644 & 0.484 \\
\hline *Traitor & 45 & 1.644 & 0.484 & *Intuition & 45 & 1.667 & 0.477 & ${ }^{*}$ Intuition & 45 & 1.667 & 0.477 \\
\hline *Intuition & 45 & 1.689 & 0.468 & *Strenuous & 45 & 1.800 & 0.405 & *Strenuous & 45 & 1.800 & 0.405 \\
\hline${ }^{*}$ Thrifty & 45 & 1.733 & 0.447 & *Thrifty & 45 & 1.822 & 0.387 & *Thrifty & 45 & 1.822 & 0.387 \\
\hline *Strenuous & 45 & 1.778 & 0.420 & *Incentive & 45 & 1.867 & 0.344 & ${ }^{*}$ Incentive & 45 & 1.867 & 0.344 \\
\hline $\begin{array}{l}\text { Valid } \mathrm{N} \\
\text { (listwise) }\end{array}$ & \multicolumn{11}{|c|}{45} \\
\hline
\end{tabular}

\section{1: Doğru cevap 2: Yanlış Cevap}

*Türkçe karşılıklarında fonolojik ve semantik benzerlikler taşımayan kontrol kelimeleri

Tablo 3'ün “Ön Test” kısmına bakıldığında, deneysel kelimeler ile kontrol kelimeler arasında istatistiksel olarak önemli farklılıklar ortaya çıktığı görülmektedir. Bu sonuçlara göre fonolojik ve semantik benzerlikleri olan kelimelerin(deneysel kelimelerin) bilinme veya hatırlanma oranları bu benzerliklere sahip olmayan kontrol kelimelerine göre çok daha yüksektir. Deneysel kelimelerden bosh, cerise ve atavism hatırlanma oranları en yüksek kelimeler olarak karşımıza çıkmaktadır. Tüm katılımcılar tarafından doğru anlamlarıyla bilinmişlerdir. Kontrol grubu olarak verdiğimiz kelimeler katılımcılar tarafından anlamları çok bilinememişlerdir ve intuition, thrifty ve strenuous kelimeleri en az hatırlanma oranına sahiptirler. Deneysel kelimelerin hatırlanma veya doğru bilinme oranı \%80, kontrol kelimelerin bilinme veya hatırlanma oranı ise \%20'de kalmıştır.

Tablo 3'ün "Son Test" kısmına bakıldı̆̆ında yine fonolojik ve semantik benzerlikleri olan kelimelerin olmayanlara nazaran çok daha fazla oranlarda hatırlandığını görülmektedir. Bu teste 
en fazla hatırlanma oranına sahip üç sözcügün yine deneysel kelime grubuna ait olduğu tespit edilmiştir. Bu kelimelerden birincisi yine bosh olmuştur, gaffe ve palaver kelimeleri de onu takip etmiştir. Hatırlanma oranı düşük son üç kelime ise kontrol kelime listesinden olmuştur; bu kelimeler strenuous, thrifty ve incentive kelimeleridir. Sonuç olarak katılımcılar deneysel kelimeleri hatırlamada kontrol kelimelerini hatırlamaya nazaran daha başarılı olmuşlardır.

Tablo 3'ün Tanıma Testi kısmına bakıldığında ise deneysel kelimelerin kontrol kelimelerden daha fazla tanındığı görülmektedir. Bosh ve gaffe kelimeleri 45 katılımcının tamamı tarafından doğru bilinmiştir. Kontrol kelimelerinden ablution ve graze tanınmada diğer kontrol kelimelerine nazaran en fazla tanınan olmuştur. En az tanınma başarısını alan kelimeler Strenuous, thrifty ve incentive olmuştur.

Tablo 4. Ön Testin Betimsel İstatistiklerinin Ortalama Sonuçları

\begin{tabular}{|l|c|}
\hline & Ortalama \\
\hline Deneysel Kelimeler & 1.216 \\
\hline Kontrol Kelimeleri & 1.560 \\
\hline
\end{tabular}

Tablo 4 deneysel kelimelerin ve kontrol kelimelerinin ön testinin betimsel istatistiklerinin ortalamalarının ortalamasını göstermektedir. Ortalamaların yüksekliği başarı ile ters orantılıdır başka bir ifadeyle 1 sayısına yakınlık başarı oranının yüksekliğini göstermektedir. Buna göre deneysel kelimelerin kontrol kelimelerine göre daha kolay hatırlandığı burada da ortaya çıkmaktadır.

Tablo 5. Son Testin Betimsel İstatistiklerinin Ortalama Sonuçları

\begin{tabular}{|l|c|}
\hline & Ortalama \\
\hline Deneysel Kelimeler & 1.213 \\
\hline Kontrol Kelimeleri & 1.776 \\
\hline
\end{tabular}

Tablo 5 deneysel kelimelerin ve kontrol kelimelerinin son testin betimsel istatistiklerinin ortalamalarının ortalamalarını göstermektedir. Aynı şekilde ortalamaların yüksekliği başarı ile ters orantılıdır başka bir ifadeyle 1 sayısına yakınlık başarı oranının yüksekliğini göstermektedir. Buna göre deneysel kelimelerin kontrol kelimelerine göre daha kolay hatırlandığ burada da ortaya çıkmaktadır.

Tablo 6 deneysel kelimelerin ve kontrol kelimelerinin tanıma testinin betimsel istatistiklerinin ortalamalarının ortalamasını göstermektedir. Tanıma testi daha öncede belirtildiği gibi çoktan seçmeli bir formda hazırlanmış bir testtir ve katılımcılar verilen İngilizce kelimelerin Türkçe doğru karşılığını yanlış cevapların içinden tanıyıp tanıyamadığı ölçülmesi amaçlanmıştır. Aynı şekilde ortalamaların yüksekliği başarı ile ters orantılıdır başka bir ifadeyle 1 sayısına yakınlık 
başarı oranının yüksekliğini göstermektedir. Buna göre deneysel kelimelerin kontrol kelimelerine göre daha kolay hatırlandığı burada da ortaya çıkmaktadır.

Tablo 6. Tanıma Testinin Betimsel İstatistiklerinin Ortalama Sonuçları

\begin{tabular}{|l|c|}
\hline & Ortalama \\
\hline Deneysel Kelimeler & 1.209 \\
\hline Kontrol Kelimeleri & 1.638 \\
\hline
\end{tabular}

\section{SONUÇ ve ÖNERILER}

Çalışma sonuçları itibariyle turizm sektörü çalışanları ve yabancı dilde kelime bilgisini artırmayı hedefleyen bireyler ve eğitimciler için önemli sonuçlar ortaya koymuştur. Araştırma Türkçe ve İngilizce fonolojik ve semantik benzerlikleri olan kelimelerin kelime öğretimine önemli ölçüde katkısının olduğunu ortaya koymaktadır. Katılımcılar kelime listesindeki kontrol kelimeleri, ön, son ve tanıma testlerinde deneysel grup kelimelerine göre çok daha başarılı bir biçimde cevaplamışlardır. Bu sonuç Türkçe karşılığında fonolojik ve semantik benzerlikleri olan İngilizce kelimelerin kelime öğretiminde kolaylık sağladığı iddiasını desteklemektedir.

Anlam ve ses sistemindeki benzerlikler açıklanarak öğretilen kelimelerin katılımcılar daha kolay ve kalıcı bir öğrenme sağladıkları ve deneysel grup kelimelerinin kontrol grup kelimelerine göre önemli bir öğrenme avantajı sağladığı tespit edilmiştir.

Öğretmenler tarafından öğrencilere kelime öğretirken bunu direk ana dilde karşılıklarını vermeden yapması ve açıklamaların bile yine yabancı dilde yapmasının önerildiği bilinmektedir. Hâlbuki Swan (1997), yukarıdaki bulguları destekler nitelikte, öğrenilen yabancı sözcügün ana dilde karşıllı̆ kolay olacağını iddia etmiştir. Aynı zamanda Taylor (1990) da aynı şeyin farklı dillerde nasıl söylendiğinin öneminin tartışılması ve karşılaştırılması gerektiğini ifade etmiştir. Bu araştırmanın sonucu her iki bilim insanının iddiaların doğrular niteliktedir; ön, son ve tanıma testlerinin sonuçları bu iddiaların öğrenme kolaylıklarının bir yansıması olduğu düşünülmektedir.

Tanıma testinde katılımcılar hatırlama testlerinden daha başarılı olmuştur. Tanıma testlerinde zaten var olan kelimelerin arasından doğru anlam taşıyan sözcüğü seçme kolaylığı ve tanımanın biçimsel özelliklerini gerektirdiği için bu sonuç şaşırtıcı değildir. Bağlamında kullanılan veya çok seçenek arasından doğru anlamlı sözcüğü tanımak veya seçmek, üretmekten daha kolaydır. Öte yandan hatırlatma testinde bağlam veya hatırlatıcılar olmadığından bu kelimelerin anlamlarını ayırt etmek ve Türkçe karşılığını tespit etmek daha zordur. Bu yüzden hatırlama ve tanıma testleri arasında tanıma testinin lehine bir miktar fark çıkması normal karşılanmalıdır. Kelimeleri benzerlik açıklamaları ile öğrenen deneklerin kelimeleri zamanla hatırlayabildiklerine dair net kanıtlar olmasına rağmen, ön ve son testlerinin ve tanıma testlerinin kendi aralarında başarı seviyelerinde farklılıklar mevcuttur ama testte deneysel kelimeler ile kontrol kelimeleri arasında deneysel kelimeler lehine istatistiksel bir başarı söz konusudur. Dolayısıyla denekler ön ve son testlerinde ve tanıma testinde deneysel kelimelerin doğru bir şekilde bilinmesinde kontrol kelimelerinin doğru şekilde bilinmesine nazaran daha başarılı olduğu ortaya çıkmıştır. 
Bu çalışmanın sonuçlarına dayanarak, öğrencilere sözcügün sadece sözlük anlamıyla değil, fonolojik ve semantik bir benzerliklerini bularak ve vurgulayarak kelime öğretilmesinin kelime öğretimine katkı sağlayacağı düşünülmektedir. Öğretmenlerin ve öğrencilerin yabancı dildeki kelimelere fonolojik ve semantik benzerlikleri sorgulayıcı bir yaklaşım içinde olması tavsiye edilmektedir.

İngilizcede kullanılan bridge (bir-üç), bergamot (bey armudu) ve caracal (karakulak) gibi Türkçe kökenli alıntı kelimeler veya ödünç kelimelerin, öğrenme ve öğretime katkılarını görmek için ileride bir çalışma yapılabilir.

$\mathrm{Bu}$ çalışma içinde fonolojik ve semantik benzerlik olan kelimelerin öğreniminin çok etkili olduğunu göstermiştir. Ses sistemi ve anlam benzerliğine sahip kelimeler ile yapılan bu çalışmanın olumlu sonuçları, bu tür çalışmalarda kullanılan deneysel yaklaşımlara katkı sağlayabileceği fikrini desteklemektedir. Farklı çalışmalar farklı erişim düzeyleri gerektirebilir. Örneğin; anlambilimsel, anlambilimsel + sözcüksel ve anlambilimsel + sözcüksel + fonolojik bilgi düzeyleri gerektirebilir. Bu yüzden bilgisayar destekli sözlük kullanımı üzerine başka bir çalışma yapmak gerekli görünmektedir. Bickel ve Truscello (1996), Felder ve Henriques (1995) farklı tipteki öğrenciler için farklı bilgi türleri sağlamak gerektiğini fikrini savunur. Buna göre bireysel farklılıklar dikkate alınarak, resimler, sesler veya videolar içeren gibi farklı sözlük türlerinin kelime öğrenimindeki etkinliği de gelecekte araştırılmaya değerdir.

Geleneksel kelime öğretiminde, öğrenciler pek çok farklı kelime ve ifadenin benzerlikler barındırmasına rağmen bu benzerliklere vurgu yapılarak öğretilmediğini görebilirler. Deneyimli öğretmenler, yabancı dil öğrencileri tarafından muhtemelen bilinmeyen kelimeleri belirleyebilse de, öğretmenlerin özellikle benzerliklere vurgu yapabileceği kelimeler üzerine çalışma yapılması gereklidir. Yine, bu çalışmamın benzeri, fonolojik ve semantik benzerlikleri olan kelimelerin bir okuma parçası içinde kullanılması şeklinde yapıldığında sonuçların nasıl değişiklik gösterebileceği önümüzdeki çalışmalara konu olabilir.

\section{KAYNAKÇA}

Alipoor, R. and Jadidi, E. (2016). The Relationship between Iranian EFL Teachers' Reflection and their Cognition about Vocabulary Teaching Style. Procedia - Social and Behavioral Sciences, 232, 769775. doi:https://doi.org/10.1016/j.sbspro.2016.10.104

Alqahtani, M. (2015). The Importance of Vocabulary in Language Learning and How to Be Taught. International Journal of Teaching and Educatio, Vol. III(3), pp. 21-34.,10.20472/TE.2015.3.3.002

Amoah, V. A. and Baum, T. (1997). Tourism Education: Policy Versus Practice. International Journal of Contemporary Hospitality Management, 9(1), 5-12.

Asadi, I. A., Khateb, A., Ibrahim, R. and Taha, H. (2017). How do different cognitive and linguistic variables contribute to reading in Arabic? A cross-sectional study from first to sixth grade. Reading \& Writing: An Interdisciplinary Journal, 30, 1835-1867.

Avery, R. ve Bezmez, S. (Eds.). (1996) Redhouse İngilizce-Türkçe Sözlük (25 ed.) İstanbul: Redhouse Yayınevi.

Batur, Z. (2008). Ana Dil Eğitiminde Hafiza-Kelimeİlişkisinin Önemi ve Hafızanın Güçlendirilmesinde Ezgili Ürrünlerin Rolü. Uşak Üniversitesi Sosyal Bilimler Dergisi, 1(1), 145-157. 
Bickel, B. and Truscello, D. (1996). New Opportunities for Learning: Styles and Strategies with Computers. TESOL Journal, 6(1), 15-19.

Biemiller, A. (2001). Teaching Vocabulary: Early, Direct, and Sequential. American Educator, 25(24), 28-47.

Chapelle, C. (1994). Are C-tests valid measures for L2 vocabulary research? Second Language Research 10, 157-187.

Christou, E. (1999). Hospitality management education in Greece An exploratory study. Tourism Management, 20, 683-691. doi:10.1016/S0261-5177(99)00039-4

Cloudia Ho, Y. Y. (2020). Communicative language teaching and English as a foreign language undergraduates' communicative competence in Tourism English. Journal of Hospitality, Leisure, Sport \& Tourism Education, 27, 1-16. 100271. doi:https://doi.org/10.1016/j.jhlste.2020.100271

Deacon, S. H., Kieffer, M. J. and Laroche, A. (2014). The relation between morphological awareness and reading comprehension: Evidence from mediation and longitudinal models. Scientific Studies of Reading, 18(6), 432-451

Dieke, P. U. C. (1988). The Development of Tourism in Kenya and Gambia: A Comparative Alanysis. Unpublished PhD Thesis. Strathclyde University. The Scottish Hotel School, Glasgow, U.K.

Felder, R. M. and Henriques, E. R. (1995). Learning and Teaching Styles In Foreign and Second Language Education. Foreign Language Annals, 28(1), 21-31. doi:10.1111/j.1944-9720.1995.tb00767.x

Frederiksen, J. R. (1982). A componential theory of reading skills and their interactions. In R. J. Mislevy (Ed.), Advances in the psychology of human intelligence. Hillsdale NJ: Lawrence Erlbaum.

Fujita, R., Terui, M., Araki, T. and Naito, H. (2017). An analysis of the English communication needs of people involved in tourism at Japanese rural destinations. Journal of Global Tourism Research, 2(1), 53-58. doi:10.37020/jgtr.2.1_53

Georgiou, G., Parrila, R., and Papadopoulos, T. C. (2008). Predictors of word decoding and reading fluency across languages varying in orthographic consistency. Journal of Educational Psychology, 100(3), 566-580.

Grabe, W. (1991). Current developments in second language reading research. TESOL Quarterly, $25,375-406$.

Hedge, T. (2000). Teaching and learning in the language classroom. China: Oxford University Press.

Heng, K. (2011). Effective Vocabulary Learning Strategies: Perspectives from Cambodian Students and Teachers. (MSc), Phnom Penh Institute of Foreign Languages Department of English, Royal Unıversity, Phnom Penh

Henning, G. (1991). A Study of the Effects of Contextualization and Familiarization on Responses to the TOEFL Vocabulary Test Items. Educational Testing Service 35, 38-45. 
Hismanoglu, M. (2000). Language learning strategies in foreign language learning and teaching. The Internet TESL Journal, 6(8) http://iteslj.org/Articles/HismanogluStrategies.html?iframe=true\&width=95\%\&height=95\% Erişim Tarihi:18.01.2021.

Hunt, A., and Beglar, D. (2004). Current research and practice in teaching vocabulary. J. C. Richards \& W. A. Renandya (Ed.), Methodology in language teaching: An anthology of current practice (s. 258-264). USA: Cambridge University Press.

Laufer, B. (1997). What's in a word that makes it hard or easy? Intralexical factors affecting the difficulty of vocabulary acquisition? In N. S. a. M. McCarthy (Ed.), Vocabulary: Description, Acquisition and Pedagogy (pp. 140-155). Cambridge: Cambridge University Press

Liao, T. Y., Hsu, P. Y., Lee, C. L., and Yang, K. F. (2017). English for Specific Purposes for EFL college interns in international tourism industry in Taiwan: Needs analysis and challenges. International Journal of Management and Applied Science, 3(7), 58-63.

Lip, P. C. H. (2009). Investigating the most frequently used and most useful vocabulary language learning strategies among Chinese EFL postsecondary students in Hong Kong. Electronic Journal of Foreign Language Teaching, 6(1), 77-87.

Little, M. M., and Dean, A. M. (2006). Links Between Service Climate, Employee Commitment and Employees' Service Quality Capability Managing Service Quality, 16 (5), 460-476.

Moisa, C. (2015). The Importance and The Role of Tourssm in The Economic And Social Life of Alba County. Annales Universitatis Apulensis Series Oeconomica, 17, 126-140. doi:10.29302/oeconomica.2015.17.1.10

Nation, I. S. P. (1990). Teaching and learning vocabulary. New York: Newbury House Publishers, Inc.

Özata, H., ve Haznedar, B. (2015). İlköğretim İkinci Sınıfta Akıcı Sözcük Okuma ve Okuduğunu Anlamayı Etkileyen Faktörler. Boğaziçi Üniversitesi Eğitim Dergisi, 35(2), 1-33.

Papadopoulos, T. C., Spanoudis, G. C. and Georgiou, G. (2016). How is RAN related to reading fluency? A comprehensive examination of the prominent theoretical accounts. Frontiers in Psychology, 7, 1-15.

Perkins, K. and Linville, S. E. (1987). A Construct Definition Study of a Standardized ESL Vocabulary Test Language Testing, 4, 125-141.

Rao, P. (2019). The importance of teaching language skills to the second or foreign language learners of english: A comprehensive study. 9(6), 6-19. doi:10.5958/2249-7137.2019.00061.2

Rhodes, G. (2006). The evolutionary psychology of facial beauty. Annual review of psychology, 57, $199-226$.

Salameh Alomoush, O. (2018). English as the Lingua Franca in Visual Touristic Jordan: The Case of Petra. International Journal of Applied Linguistics and English Literature 7 (4 ), 1-13.

Stahl, S. A. (1999). Vocabulary Development. Cambridge: Brookline Book. 
Stanovich, K. E., and West, R. F. (1989). Exposure to print and orthographic processing. Reading Research Quarterly, 24(4), 402-433.

Swan, M. (1997). The Influence of the Mother Tongue on Second Language Vocabulary Acquisition and Use. In N. S. a. M. McCarthy (Ed.), Vocabulary: Description, Acquisition and Pedagogy (pp. 156-180). Cambridge: Cambridge University Press.

Taylor, L. (1990). Teaching and learning vocabulary. London: Prentice Hall International (UK) Ltd.

Thompson, I. (1987). Learner Strategies in Language Learning. Englewood: Prentice Hall.

Tosun, C. (1999). Towards a Typology of Community Participation in the Tourism Development Process. Anatolia, 10(2), 113-134. doi:10.1080/13032917.1999.9686975

Tovar Viera, R. (2016). The importance of vocabulary knowledge in the production of written texts: a case study on EFL language learners. Revista Tecnológica ESPOL -RTE, 30 (3), 89-105.

Zagonari, F. (2009). Balancing Tourism Education and Training. International Journal of Hospitality Management, 28, 2-9. doi:10.1016/j.jhm.2008.03.006 